\title{
LOW CYCLE FATIGUE OF BINARY Al-Li ALLOYS. II-MICROSTRUCTURAL CHARACTERIZATION AND IN SITU FATIGUE EXPERIMENTS
}

\author{
Y. BRECHET, F. LOUCHET and J.L. VERGER-GAUGRY \\ Laboratoire de Thermodynamique et Physico-Chimie \\ Métallurgiques, ENSEEG, Domaine Universitaire, B.P. 75 , \\ F-38402 Saint-Martin-d'Hères Cedex, France
}

\section{ABSTRACT}

The fatigue behaviour of AlLi binary alloys is investigated at the microscopic scale using T.E.M., STEM, and in situ fatigue in T.E.M. on specimens previously fatigued in torsion. In the $\mathrm{Al} 0.7 \% \mathrm{~L}$ solid solution, a cell structure is observed. The A12.5\%Li alloy with small precipitates exhibit precipitate free bands which reflect a strong localization. The $A 12,5 \%$ i alloys with large precipitates show Orowan by passing but also shearing by the Orowan Loops. The three types of mechanisms were observed also by in situ straining experiments in the T.E.M.

\section{I- INTRODUCTION}

Aluminium alloys strengthened by $\mathrm{Al}_{3} \mathrm{Li}$ precipitates are known to have a short fatigue lifetime. Failure occurs rather by transgranular or by intergranular fracture, depending on the annealing time. The purpose of the present work is to clarify the problem of strain mechanisms and localization in fatigue in the simplest case, that of a binary alloy, with variable Li content and precipitate size.

The macroscopic aspects of the fatigue behaviour of three types of binary Al$\mathrm{Li}$ alloys are described by $\mathrm{S}$. Han and $\mathrm{B}$. Wack in the present conference (1). The same alloys are studied here under the microscopic point of view, using SEM, TEM and STEM techniques, and in situ TEM fatigue tests.

\section{II- EXPERIMENTAL}

- Three types of alloys are used, which have been provided by Cegedur Pechiney, and cyded in torsion at imposed total deformation amplitude

$1 / 2 \quad t=3.10^{-3}$, and $5 \times 10^{-3}$, with a strain rate of $10^{-3} \mathrm{~s}^{-1}$

- Alloy A is a solid solution. Alloys B and C contain ordered coherent precipitates $\left(A I_{3} \mathrm{Li}\right)$, of $\mathrm{L}_{12}$ structure, which have been grown to different sizes by adjusting the anhealing time and temperature (2), according to the following table :

\begin{tabular}{|c|c|c|c|}
\hline Type of alloy & A & B & C \\
wt.\%Li & 0.7 & 2.5 & 2.5 \\
average radius of & $\begin{array}{c}\text { solid } \\
\text { solution }\end{array}$ & $1.5 \mathrm{~nm}$ & $20 \mathrm{~nm}$ \\
\hline
\end{tabular}

The microstructure has been analyzed using a $200 \mathrm{CX}$ JEOL TEM, and a VG HB5O1 STEM operating at $100 \mathrm{kV}$ and equipped with a Tracor Northern TN 2000 analyzer. In situ fatigue tests are performed at room temperature, using a "home made" specimen holder which operates in shear, on thin foils cut parallel to the surface of macroscopic specimen, in order to keep the same local stress tensor. 


\section{III- ALIOY A}

The solid solution after fatigue exhibits only a cell structure, the operation of which can be observed in situ (fig.1). Dislocations bend under stress out of sources in cell walls, escape suddenly from them, and travel across the cell. Some of them insert into the opposite wall. During the following half-cycle, their curvature is reversed. Most of them cross-slip and travel across the cell on different slip planes, as indicated by the slip traces visible on the figure, and demonstrating slip irreversibility.

Although persistent slip bands are likely to form at lower strain amplitudes, as shown by Dhers in pure Al fatzigured in tension/compression (3), in our case, for strain amplitudes of some $10^{-3}$, the operation of cell structures described above is probably dominant.

\section{IV- ALLOY B}

The fatigue behaviour of alloy B with small shearable $\delta$, precipitates $(R \cong 1.5 \mathrm{~nm})$ has been discussed elsewhere (4) and will be only summarized here. The microstructure of fatigued specimens does not exhibit any cell structure. In situ fatigue tests show dislocation avalanches localized in narrow slip bands (fig.2), and superlattice dark field images taken with the electron bean parallel to a [112]] direction show narrow channels parallel to (111) slip planes, with a width of about $5 \mathrm{~nm}$, in which $\delta$, precipitates are not visible (fig.3). On the other hand, b'precipitates are clearly visible between channels, and exhibit a strong coarsening on band sides.

Filtered EELS images have been obtained in STEM, using two energy windows on both sides of the average plasmon peak (at $14.7 \mathrm{eV}$ for the $2.5 \mathrm{wt} \% \mathrm{Li}$ alloy $\{9.68$ at \%) the images obtained with the high energy window show bright bands on a dark background (fig.4), and those with the low energy window have a reversed contrast. Since the energy of the plasmon peak is given by :

$$
E(\mathrm{eV}): 15.09-3.97 \mathrm{C}_{\mathrm{Li}}(\mathrm{at \%})
$$

according to (5), the observed contrasts agree with a strong decrease of $\mathbf{L i}$ concentration inside the bands. The advantage of this method is to get rid of the eventual influence of thickness on the observed contrast. Concentration profiles of Li have also been performed in EELS, with a probe size around $1 \mathrm{~nm}$, and a step of $5 \mathrm{~nm}$. We obtain $\mathrm{C}_{1} \sim 4$ at $\%$ inthe bands, whereas the average $\mathrm{Li}$ concentration measured by this technique is 9.8 at\%. A local enrichment in Li (C $\sim 12$ at\%) is also noticed on band sides, in agreement with the superlattice dark field observations.

- The model we propose for the formation of channels deprived of $\mathrm{Li}$ during fatigue is based on a modification of the size dependence of the free energy of precipitates when steps and antiphase boundaries are introduced by shear. It can be easily shown (5) that the enezrgy of a sheared precipitate can be written :

$$
\Delta G(R)=-(4 / 3 \pi) \pi \tilde{Y}_{Y} R^{3}+4 \pi \tilde{Y} R^{2}
$$

where $R$ is the precipitate radius, and where $\tilde{\gamma}$ and $\tilde{\gamma}$ are equivalent volume and surface specific energies, which depend on the shear strain

$$
\begin{aligned}
& \tilde{\gamma}_{v}=\gamma_{v} \cdot\left(1-\gamma_{a} \tilde{\varepsilon} / b \cdot \gamma_{v}\right) \\
& \tilde{\gamma}_{s}=\gamma_{s} \cdot(1+\pi \tilde{\varepsilon} / 8)
\end{aligned}
$$

$\gamma$ a being the antiphase energy, and $\tilde{\varepsilon}$ an equivalent shear strain which takes into account the possibility for an antiphase boundary to be erased by a second dislocation shearing the precipitate along the same plane.

From eq. (1), the critical radius for precipitate dissolution (saddle point of $\Delta G(R))$ defined by $(\gamma \Delta G / \partial R)=0$ is $\tilde{R}_{c}=2 \tilde{Y}_{S} / \tilde{Y}$. since $\tilde{\gamma}_{V}$ becomes

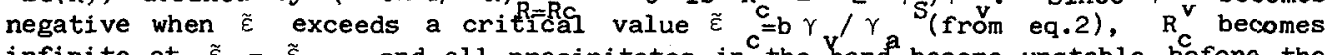
infinite at $\tilde{\varepsilon}=\tilde{\varepsilon}$, and all precipitates in the band become unstable before the cumulative equivalent strain $\tilde{\varepsilon}$ is reached locally, which corresponds to a critical time $t_{c}=\tilde{\varepsilon} / \dot{\varepsilon}_{\text {log }}$, and a locăl strain estimated to about $20 \%$ in the present case. More precisely, 'Igk' has to be compared to the actual size of precipitates, which slowly increases in $t 1 / 3$ during fatigue according to a lifschitz-Slyozov-Wagner law, (2), and which will necessarily cross the $\widetilde{R}_{c}(t)$ curve at a time $t_{a}=t_{c}$, at which the $\delta^{t}$ precipitates become unstable and dissolve. 


\section{V- ALLOY C}

- In this case, precipitates are large, and are expected to be by-passed by Orowan looping. In situ experiments indeed show at $\Delta \sigma=250 \mathrm{MPa}$ by-passing events (fig.5) in which loops produced by a dislocation during a half-cycle are often annihilated by the same dislocation during the following half-cycle, but where cross slip events during the to and fro movement of the dislocation can accumulate opposite loops in stead of annihilating them, which is probably responsible for part of the fatigue irreversibility.

- However, superlattice dark field observations show that a number of precipitates are sheared, in spite of their size (fig.6), which was not expected in Orowan Looping conditions. If we assume that they are sheared not by moving dislocations, but by Orowan loops under a driving force due to the line tension of the loop and to the applied stress, the increase of energy when the loop has penetrated a distance $\mathbf{x}$ in the precipitate is :

$$
\delta W(x)=-\pi\left(\gamma_{a}-\sigma b\right) x^{2}+2 \pi R x\left(\gamma_{a}-\sigma b-\Gamma / R\right)
$$

where $\gamma$ is the APB energy, $\Gamma$ the line tension, and $R$ the precipitate radius. This energy göes through a maximum (saddle point) :

for $x=x_{m}=R \quad\left(1-R\left(\frac{\Gamma}{\left.\gamma_{a}-\sigma b\right)}\right)\right.$

$$
W_{m}=\pi R^{2} \cdot\left(\gamma_{a}-\sigma b\right) \cdot\left(1-\frac{r}{\left(\gamma_{a}^{-\sigma b}\right) R^{-}}\right)^{2}
$$

If the saddle point energy has to be provided only by thermal activation (at $\sigma=0)$ this would give $w_{n}(\sigma=0) \simeq 500 \mathrm{eV}$ with $\mathrm{R}=200 \AA, b=2.8 \AA, \quad \gamma_{a}=140 \mathrm{~mJ} / \mathrm{m}^{2}, \Gamma=$ $1.34 \times 10^{-9} \mathrm{~J} / \mathrm{m}$. A pure thermally activated shearing during the storage of specimens before TEM observations is then quite unlikely. On the contrary, the critical resolved shear stress $\sigma$ c which reduces the energy barrier to zero is given by :

$$
\sigma_{c}=\frac{1}{b} \cdot\left(\gamma_{a}-\frac{\Gamma}{R}\right) \sim 250 ! 1 \mathrm{~Pa}
$$

which corresponds to an applied shear stress of about 500 MPa (taking into account an average Schmid's factor). This stress level is not reached during fatigue (maximum stress $\simeq 150 \mathrm{MPa}$ ), but if two loops pile up around a precipitate on the same slip plane, the APB is reduced to the surface between the loops while the stress on the leading dislocation is significantly increased. Shearing is then possible for a local strain $\varepsilon=n \cdot b / 4 R_{0} \quad$ (with $n=2$ ) $\simeq 0.7 \%$, which can be easily reached at $1 / 2 \Delta \varepsilon=0.3 \%$ by a slight strain localization.

Orowan looping and subsequent precipitate shearing by Orowan loops can operate even without the help of any thermal activation in the present conditions. The domains of stress in which these two processes occur can eventually overlap, since the Orowan looping is determined by the stress and the spacing between precipitates, and the shearing by Orowan loops by the stress, the line tension, the antiphase boundary energy and the strain localization. This strain localization is both the cause and the consequence of precipitate shearing, and therefore increases during fatigue, while large volumes of the specimen contribute to the fatigue strain by small and quasi reversible movements of dislocations. Another reason for strain localization is that PFZ's have grown along grain boundaries during annealing, and most of the strain is observed to localized in these PFZ, where dislocations move much more freely than in the grains.

\section{CONCLUSION}

The fatigue behaviour of the solid solution AlLi is characterized by an homogeneous and irreversible motion of dislocations in a well defined cell structure. On the opposite, alloys hardened by small $\delta$ ' precipitates exhibit a strong strain localization in narrow slip bands in which precipitates become readily unstable by accumulation of APB's and dissolve.

In the case of large precipitates, Orowan looping prevails in the grains, but Orowan loops can easily shear the precipitates if strain is somewhat localized. Strain localization also occurs in PFZ's, where dislocations move much more freely than in the interior of grains. 

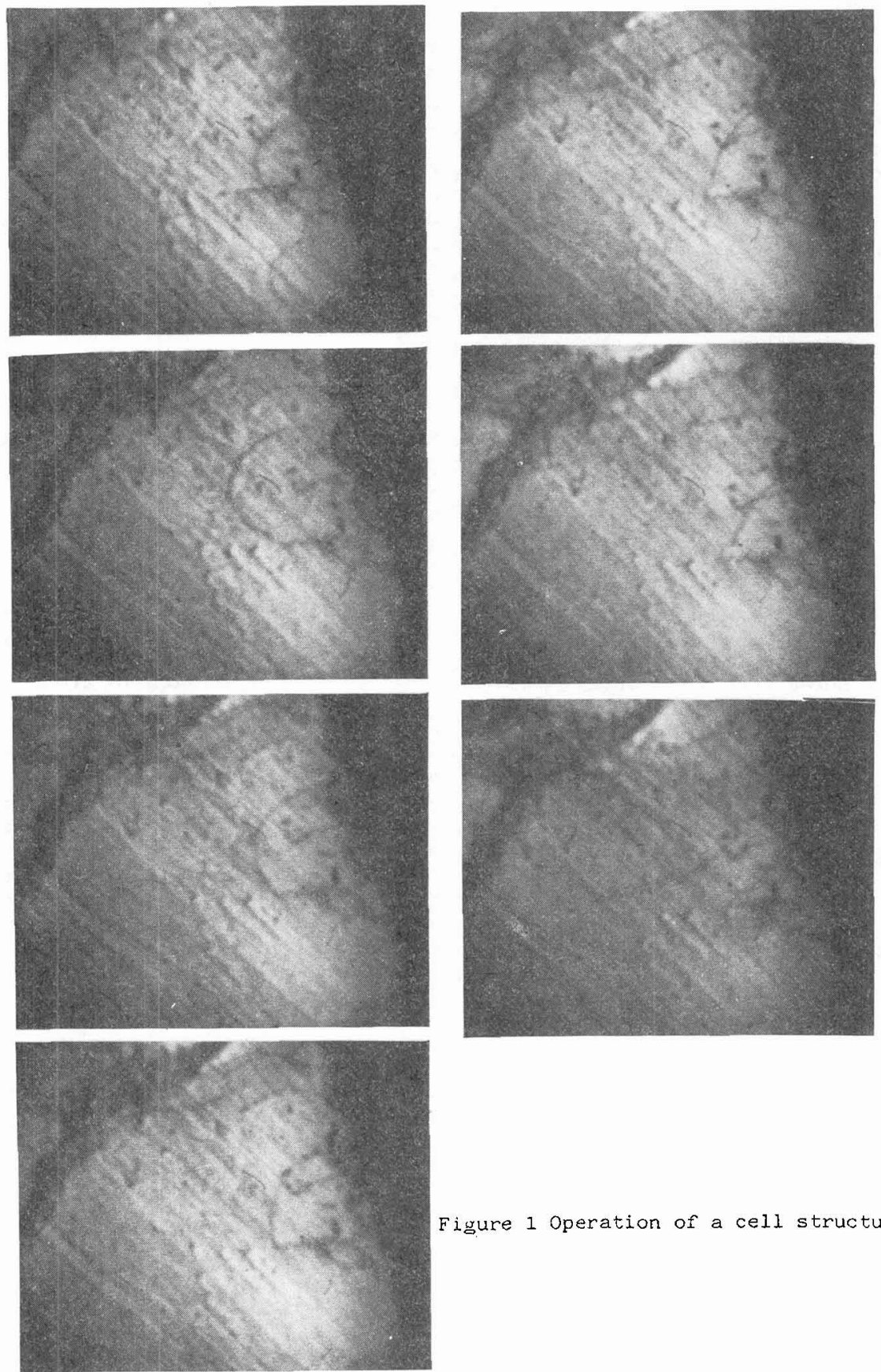

Figure 1 Operation of a cell structure (A) 

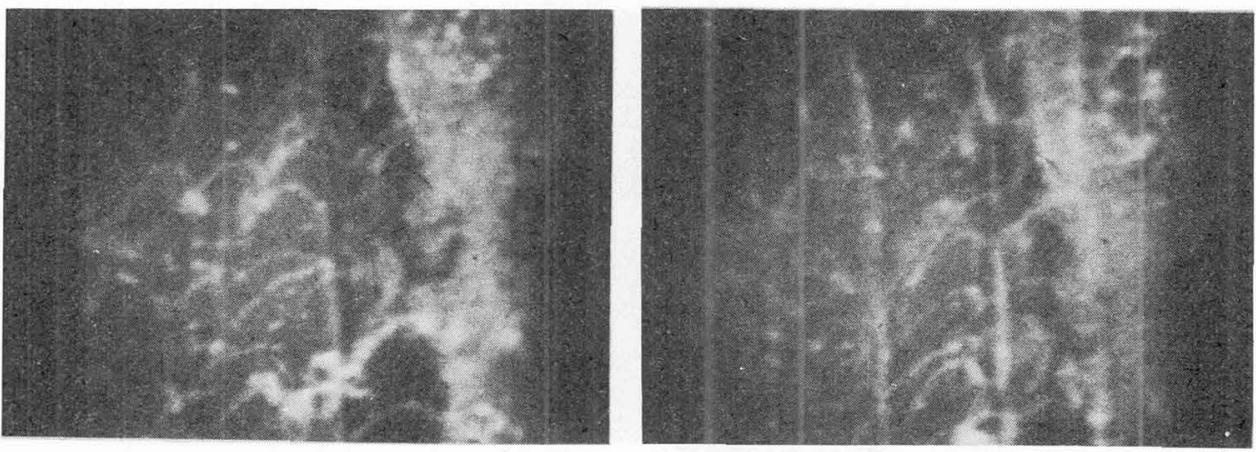

Figure 2 in situ avalanches (B)
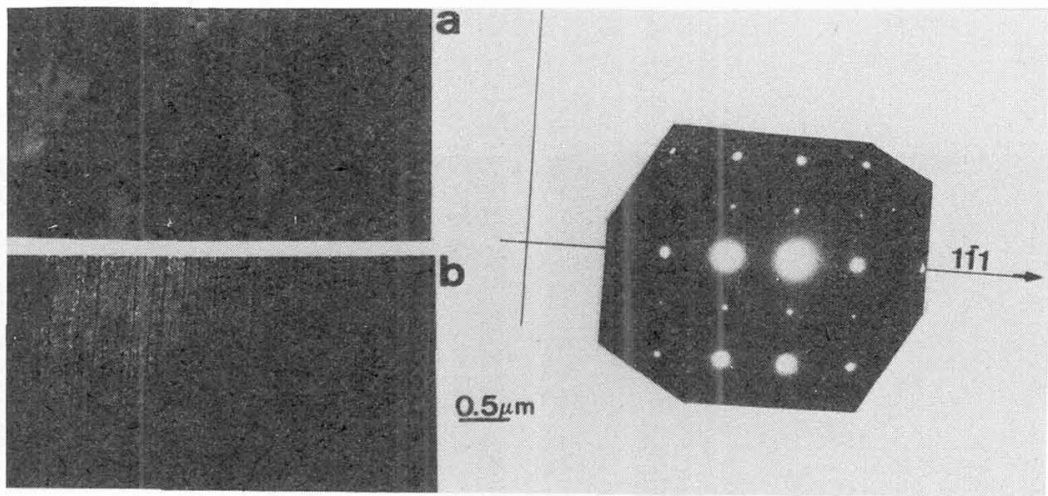

Figure 3 dark fiela superlattice $(B)$ 


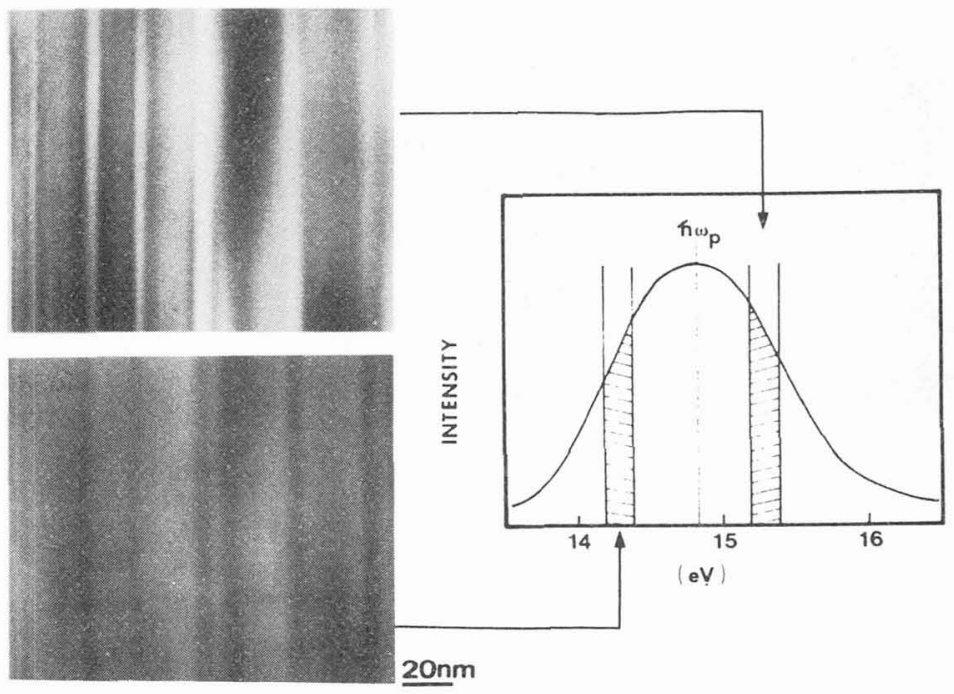

Figure 4 EELS filtered images (B)
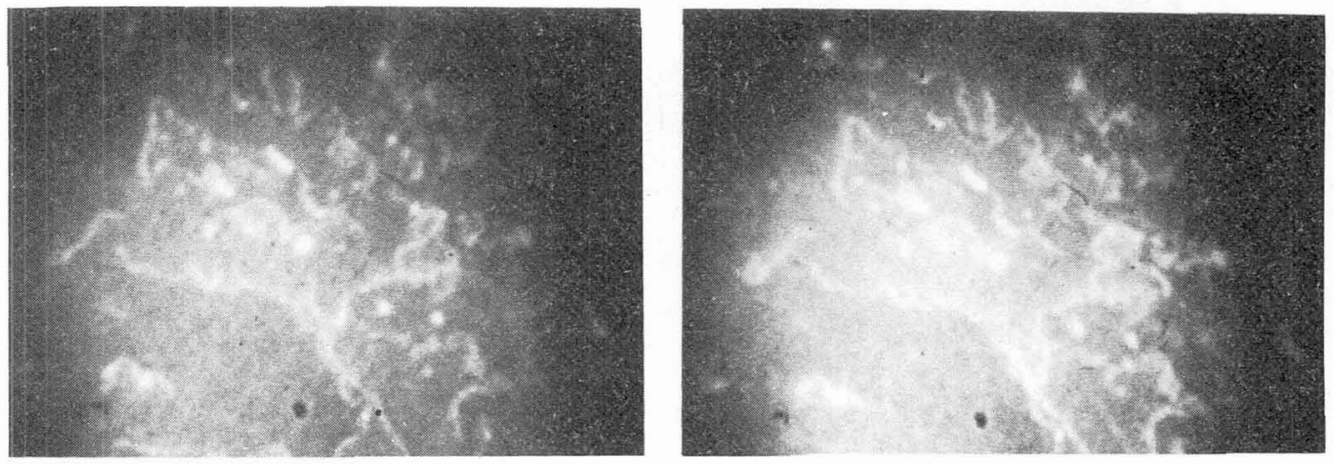

Figure 5 Orowan bypassing of precipitates

(in-situ straining ) -Alloy C 


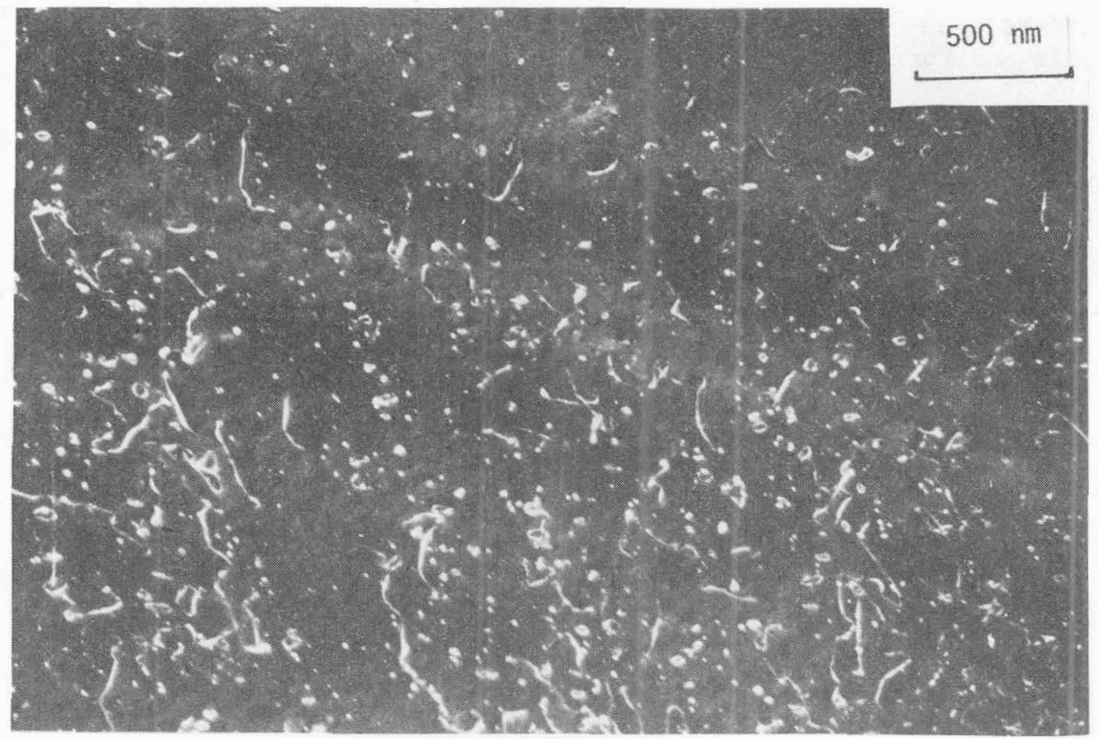

Figure 6 Orowan's loops (weak beam image) and sheared precipitates (dark field on a surstructure spot 110 )-Alloy C

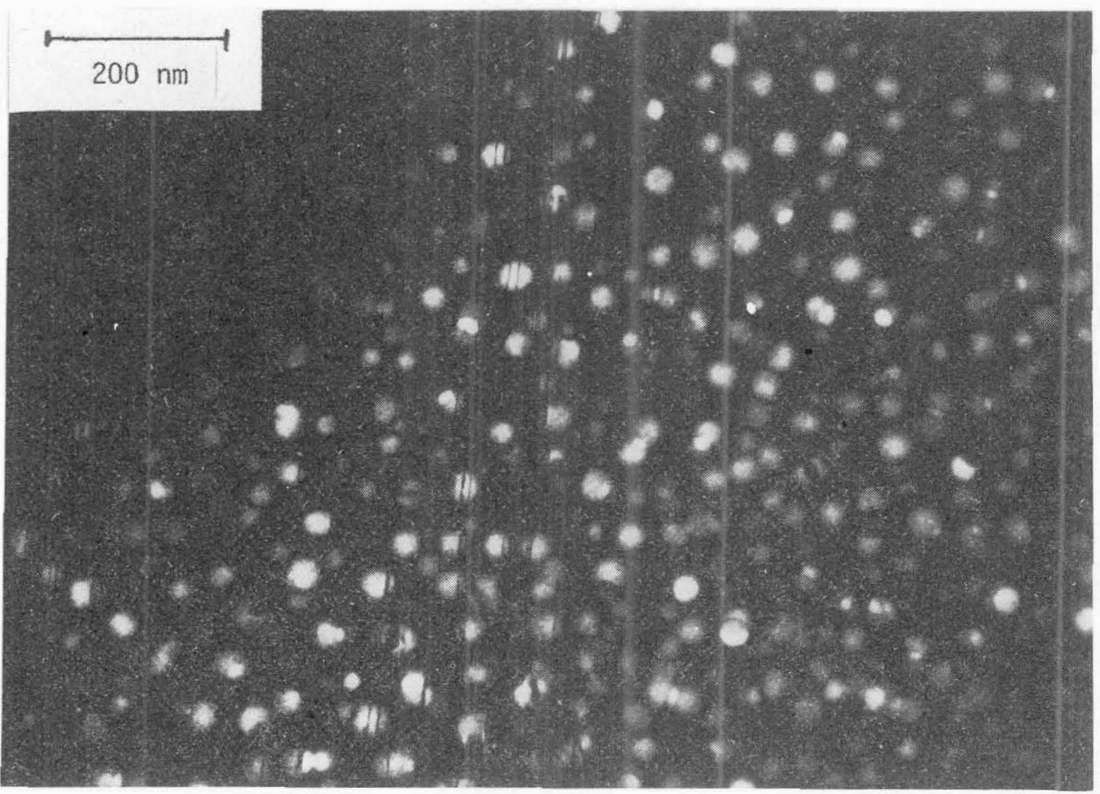


ACKNOWLDGENTSS The authors thanks Aluminium Pechiney Company for having provided the materials and for financial support of of them (Y.B.).

\section{REFERENCES}

(1) S. HAN, B. WACK This conference ("paper I")

(2) Y. BRECHET, F'. LIVET, This conference ("paper III")

(3) J DHERS, Thesis St Etienne 1986

(4) Y. BRECHET, F. LOUCHET, J.L. VERGER-GAUGRY, Phil. Mag. under press.

(5) P. SAINFORT Thesis Grenoble University, 1985. 